\title{
Conceptos y metodología de la investigación histórica*
}

\author{
Concepts and methodology of historical research
}

\section{Gregorio Delgado García}

Historiador Médico del Ministerio de Salud Pública. J efe del Departamento de Historia de la Salud Pública. Escuela Nacional de Salud Pública. La Habana, Cuba.

\begin{abstract}
RESUMEN
Se exponen brevemente los conceptos fundamentales de la historia como ciencia social, tales como su objeto, sujeto y fin y la más abarcadora concepción de la filosofía de la historia. Se exponen también sus métodos de investigación como el analítico-sintético, en que juega un gran papel la síntesis heurística que lleva de lo general a lo particular (deductiva) y que es el método histórico por excelencia, pero completándolo con la síntesis hermenéutica de lo particular a lo general (inductiva). Se destaca la importancia de submétodos como el cronológico, geográfico y etnográfico. Se citan y explican otras ciencias auxiliares fundamentales como la arqueología, la paleografía, la epistemología o gnoseología, la numismática, la diplomática, la sigilografía o esfragística, la heráldica, la genealogía, la iconografía, la filatelia y la antropología; también de las fuentes escritas y orales en la investigación histórica, sin menospreciar las tradiciones y los monumentos y las diferentes maneras de reseñar la historia como las crónicas, las efemérides, las décadas, las memorias y sobre todo el ensayo histórico. Se presenta la muy utilizada división de la historia en universal, general, nacional, provincial, local, institucional, genealógica, biográfica y autobiográfica, ilustrándolas lo más posible con ejemplos de obras de autores cubanos, para terminar con la exposición de las periodicidades más frecuentemente empleadas por historiadores burgueses y marxistas.
\end{abstract}

Palabras clave: Investigación histórica.

\section{ABSTRACT}

This paper briefly presented the main concepts of history as social science, its object, subject and aims, the most comprehensive conception of the philosophy of 
history as well as the research methods of this science such as the analyticalsynthetic method - the historical method par excellence- in which heuristic synthesis going from generalization to particularization (deductive) plays the major role, supplemented with the hermeneutic synthesis going from particularization to generalization (inductive). The importance of the chronological, geographical and ethnographic sub-methods was underlined. Other fundamental associated sciences like archeology, paleography, epistemiology or gnoseology, numismatics, diplomacy, sigillography, heraldry, genealogy, iconography, philately and anthropology were mentioned and explained. Also, written and oral sources of historical research including traditions, monuments and a variety of ways to history review, memoirs and historical assays were taken into consideration. The commonly used classification of history into universal, general, national, provincial, local, institutional, genealogical, biographical and autobiographical was provided and exemplified as much as possible with the works by Cuban authors. Finally, the most frequent periodization used by bourgeois and marxist historians was set out.

Key words: Historical research.

\section{NTRODUCCI ÓN}

La historia es una de las ramas más importantes del conocimiento humano, base fundamental de la cultura de todo profesional, no importa cual sea su especialidad y sobre todo, fuente imprescindible para la formación ideológica de los ciudadanos de cada país.

No es posible concebir un miembro de una comunidad social sin el conocimiento preciso de su historia. Esto, indiscutiblemente, le permitirá amar sus raíces, comprender el presente y ayudar conscientemente a forjar el futuro de su país y de la humanidad.

El objetivo general que se propone este artículo es que se conozcan los conceptos más importantes de la historia como ciencia social y sus métodos y submétodos de estudio, para lo cuál se plantean los siguientes objetivos específicos: a. Definir brevemente el objeto, sujeto y fin de la historia así como exponer el concepto de Filosofía de la Historia. b. Explicar sus métodos y submétodos de investigación. c. Enumerar sus ciencias auxiliares y fuentes en que se nutre. d. Dar a conocer las más importantes formas de reseñarla. e. Explicar su división más aceptada y algunas de las periodicidades más utilizadas.

\section{OBJ ETO, SUJ ETO Y FI N DE LA HISTORIA}

Sin entrar en polémicas sobre análisis conceptuales de la historia seguiremos al viejo maestro de historiadores cubanos, el profesor Juan Martín Leiseca, quién definía el objeto esencial de la historia simplemente como la reseña de los sucesos pasados y no existe la menor duda de la certeza de sus palabras. 
Para él, el sujeto de la historia es el hombre y su fin, presentar a los hombres actuales el relato y consecuencias de los hechos del pasado, para que por el estudio y comparación de esos hechos encuentren enseñanza y guía en su labor del porvenir.

Pero estas definiciones deben ser llevadas para su completamiento al campo de la Filosofía de la historia que conceptualmente es la narración analizada, comentada y comparada de los hechos históricos y es esta la única forma en que llena su fin la historiografía.

\section{MÉTODOS Y SUBMÉTODOS DE ESTUDIO}

El método de investigación histórica es el analítico-sintético. Es indispensable que en el estudio de las cuestiones históricas se analicen los sucesos descomponiéndolos en todas sus partes para conocer sus posibles raíces económicas, sociales, políticas, religiosas o etnográficas, y partiendo de este análisis llevar a cabo la síntesis que reconstruya y explique el hecho histórico.

El método analítico es el heurístico, palabra que proviene del término griego heurisko que quiere decir yo busco, descubro, y que es el método que se usa para encontrar lo nuevo, lo que se desconoce. En historia sería el manejo de las fuentes escritas y orales principalmente, aunque para el estudio de la prehistoria habría que recurrir a otras ciencias auxiliares de las que se hablará más adelante. El eminente periodista, diplomático e historiador don Manuel Márquez Sterling en su trabajo de ingreso en la antigua Academia de la Historia de Cuba, titulado "En torno de la heurística" (1929), hace un interesante comentario sobre dicho procedimiento investigativo.

El método de síntesis es el hermenéutico, palabra que proviene del término griego hermeneuo, que quiere decir yo explico y que consiste en el arte y teoría de la interpretación, que tiene como fin aclarar el sentido del texto partiendo de sus bases objetivas (significaciones gramaticales de los vocablos y sus variaciones históricamente condicionadas) y subjetivas (propósitos de los autores). Este método es muy utilizado también en teología y recientemente el autor ha tenido oportunidad de leer un impecable estudio hermenéutico del doctor Evis $\mathrm{L}$. Carballosa Vidaud, teólogo bautista sobre la "Epístola a los Romanos" del Apóstol San Pablo en su libro "Romanos. Una orientación expositiva y práctica" (1994).

La investigación histórica también es deductiva-inductiva. Deducción, palabra que proviene del latín deductio, que quiere decir sacar consecuencias de un principio, proposición o supuesto, se emplea para nombrar al método de razonamiento que lleva a la conclusión de lo general a lo particular. Este método en historia es fundamental, no es posible conocer y explicarse la historia local del municipio de Güines si no se parte del conocimiento de la historia nacional de Cuba y de esta si no se hace a partir de la historia de América y de España.

Inducción, término que procede del latín inductio, que quiere decir mover a uno, persuadir, instigar, nombra al método de razonamiento que asegura la posibilidad de pasar de los hechos singulares a las proposiciones generales, o sea de lo particular a lo general. Aunque la historia general de un país no es exactamente la suma de sus historias locales, es muy importante conocer los hechos particulares para alcanzar las conclusiones más reales en los resultados de la investigación histórica. 
Por lo tanto el método de investigación histórica debe ir de lo general a lo particular, pero debe ser completado de lo particular a lo general.

Entre los principales submétodos de investigación histórica se encuentran el cronológico, el geográfico y el etnográfico. El cronológico es el más importante. Cronología proviene del nombre griego Cronos, que es el Dios del Tiempo, por lo tanto el conocimiento del desarrollo de los hechos por orden sucesivo de fechas es imprescindible en toda investigación histórica. A partir de ella se facilita extraordinariamente la interpretación histórica. A veces constituye en sí una investigación como es el utilísimo libro del notable historiador médico doctor J osé A. Martínez-Fortún Foyo "Cronología Médica Cubana. Contribución al estudio de la Historia de la Medicina en Cuba" (1947-1958), publicado en 16 fascículos.

El submétodo geográfico es el que trata los sucesos por orden de pueblos. No es posible escribir la historia de un país o una región si no se tiene un conocimiento acabado de su geografía. En Cuba no han sido pocos los historiadores geógrafos como son los casos de los doctores Tomás Justiz del Valle y José M. Pérez Cabrera, ni tampoco los geógrafos historiadores como los doctores Leví Marrero Artiles y Antonio Núñez Jiménez.

Y por último, el submétodo etnográfico que relaciona los hechos históricos por razas, nacionalidades, religiones, manifestaciones culturales y otras. Como ejemplo de este submétodo está la extraordinaria obra total histórico-etnológica del sabio cubano don Fernando Ortiz Fernández, de la que no se puede dejar de citar sus libros: "Los negros brujos"(1906), "Los negros esclavos"(1916), "El engaño de las razas"(1946), "Los bailes y el teatro de los negros en el folklore de Cuba"(1951) y los "Instrumentos de música afrocubanos"(1952-1955), este último en cinco tomos, así como la más reciente de la investigadora Natalia Bolívar Aróstegui, en la que se destaca "Los orichas en Cuba"(1990).

\section{ENCI AS AUXI LI ARES Y FUENTES EN QUE SE NUTRE LA HISTORI A}

Se han revisado como submétodos la aplicación a la historia de tres ciencias muy importantes como son la cronología, la geografía y la etnología, ahora se enumeraran otras ciencias, también de importancia su conocimiento, como auxiliares de la historia.

La arqueología, ciencia que investiga los monumentos no solo en sus valores intrínsecos sino también en su evolución en el tiempo y que incluye artes como la arquitectura, la pintura, la escultura y la epigrafía, esta última comprende el estudio de las inscripciones. Como ejemplo de dicha ciencia auxiliar de la Historia está el libro de Eugenio Sánchez de Fuentes "Cuba monumental, estatuaria y epigráfica" (1916) e "Historia de la Arqueología Indocubana" (1922), del doctor Fernando Ortiz.

La paleografía, que estudia las escrituras antiguas. Para un historiador cubano es muy importante el conocimiento de la gramática del castellano antiguo y el latín. Como ejemplo de investigación en estas ciencia están las obras: "Lexicografía Antillana" (1914), del doctor Alfredo Zayas Alfonso y "Léxico Cubano" (1946), en dos tomos, del filólogo, lingüista e historiador Juan M. Dihigo Mestre.

La epistemología o gnoseología, que comprende el estudio de la teoría del conocimiento, muy utilizada por los historiadores ingleses y norteamericanos. En 
Cuba su principal propagador fue el doctor Luis A. Baralt Zacharie, hijo del médico de José Martí, doctor Luis A. Baralt Peoli, que fundó y desempeñó la cátedra de Teoría del Conocimiento en la Universidad de La Habana de 1934-1960.

La numismática, que estudia las monedas y medallas antiguas y modernas. Cuba posee un rico museo de numismática adscrito al Banco Central, situado entre Cuba y Amargura, calles de La Habana Vieja. El doctor Nicolás J. Gutiérrez Hernández, fundador de la prensa médica en el país y de la Academia de Ciencias Médicas, Físicas y Naturales de La Habana, fue un notable coleccionista y estudioso de monedas antiguas.

La diplomática, que estudia los diplomas y documentos oficiales. Un aporte a esta ciencia lo es "Constituciones de la República de Cuba" (1952), edición facsimilar, obra publicada por la antigua Academia de la Historia de Cuba.

La sigilografía o esfragística, que estudia los cuños de instituciones o personas y los signos de los escribanos. El destacado investigador del pasado cubano, doctor César García del Pino y la paleógrafa y delineante Alicia Melis Cappa, publicaron en 1982 la interesante obra "El libro de los escribanos cubanos de los siglos XVI,XVII y XVIII", en que reproducen y estudian 172 signos usados en Cuba por escribanos de dichos siglos, el primero de 1531 y el último de 1788.

La heráldica, que investiga los escudos de países, provincias, municipios y principalmente de familias. Durante varios años el investigador Antonio N. de León publicó en el periódico "El Mundo" una sección sobre heráldica de familias cubanas. También existió un Instituto Cubano de Heráldica y Genealogía que presidió el notable genealogista Rafael Nieto Cortadellas.

La genealogía, que estudia las familias. En la primera mitad del siglo xx esta ciencia auxiliar de la historia fue muy desarrollada en Cuba y su figura principal lo es don Francisco Javier de Santa Cruz y Mallén, conde de San Juan de Jaruco y Santa Cruz de Mopox, con su extensa obra "Historia de Familias Cubanas" en seis tomos.

La iconografía, que estudia las fotografías. El doctor Benigno Souza Rodríguez publicó en el rotograbado del Diario de la Marina por los años de la década de 1940 su importante "I conografía de la Guerra del 95" y Arturo R. de Carricarte de Armas su "I conografía del apóstol Martí" (1925).

La filatelia que estudia los sellos de correo. Cuba posee un rico museo de la Filatelia adscrito al Ministerio de Comunicaciones, en la Plaza de la Revolución de La Habana. Una aplicación de esta ciencia a la historia de la medicina es el libro del doctor Ernesto Bello Hernández "Las Ciencias Médicas en la Filatelia Cubana" (1970).

Y no porque se ha dejado para citarla al final, deja de tener una gran importancia. Se trata de la antropología o estudio del hombre, cuyas investigaciones se desarrollaron en Cuba desde el siglo XIX, principalmente a partir de su segunda mitad, por el doctor Luis Montané Dardé. Esta ciencia la constituyen numerosas ramas como la antropología general, física, comparada, arqueológica, social, médica y otras, todas de gran valor para la historia en general y para la historia de la medicina en particular.

Entre las fuentes de las que se nutre la historia están en primer lugar los escritos o documentos, que constituyen las fuentes escritas y que son las más importantes. Se ha dicho, con sobradas razones, que la historia comienza con la escritura y que 
sin documentos no se la puede escribir. Ejemplos de la importancia del documento es el ensayo "El documento y la reconstrucción histórica" (1929), del erudito investigador de las letras cubanas doctor José M. Chacón y Calvo; la obra "Documentos para la Historia de Cuba" (1968-1980), en cinco tomos, de la doctora Hortensia Pichardo Viñals; el libro "La guerra de Cuba en 1878 (La Protesta de Baraguá)" (1973), colección de documentos del médico y general mambí Félix Figueredo Díaz, recopilados por el académico César Rodríguez Expósito y el monumental "Centón Epistolario de Domingo Del Monte"(1923-1957), obra en siete tomos, editada por la Academia de la Historia de Cuba, en que se recoge el rico archivo epistolar de tan importante figura histórica cubana.

En historia de la medicina los principales documentos los constituyen los libros, folletos y artículos médicos, de ahí la importancia del estudio de la bibliografía. Ejemplo de lo anterior son las obras: "Bibliografía Médico-Farmacéutica Cubana (1707-1905)" (1906); "Bibliografía Científica Cubana" (1919), tomo II dedicado a las ciencias médicas, en el que se mencionan 4420 libros, folletos y artículos de 1 100 autores y "Contribución de los médicos cubanos a los progresos de la Medicina. Ojeada a la literatura médica cubana" (1926), todas del sabio bibliógrafo Carlos M. Trelles Govín y las no menos importantes del doctor Jorge Le Roy Cassá sobre bibliografía de grandes figuras de la Medicina Cubana que ascienden a dieciséis.

Los testimonios constituyen las fuentes orales y le siguen a la escritura en importancia, sin embargo, es necesario repetir que no bastan estas últimas como únicas fuentes para escribir la historia, ellas en muchas oportunidades sirven de guía para la búsqueda de los documentos imprescindibles. Siempre se citan las memorias de los participantes en hechos históricos como los testimonios de más valor, pero para que esto sea cierto es preciso que esas narraciones tengan como base diarios de actividades escritos cuando se producían los hechos y la consulta de fuentes escritas. Uno de los más eminentes historiadores del siglo xx, el profesor inglés Arnold J. Toymbee ha dejado escritas importantes páginas sobre las ventajas y limitaciones del testimonio como fuente histórica en su imprescindible libro "A Study of History" (1946), doce tomos.

El testimonio puede producirse espontáneamente por el testimoniante como en "Pasajes de la guerra revolucionaria" (1963), del comandante Ernesto Guevara de la Serna y "Diario de Cabo Haitiano a Dos Ríos" (1941), de José Martí Pérez o en entrevista concedida al investigador, como "Secretos de Generales" (1996), por Luis Báez Hernández, obra que contiene 41 importantes entrevistas.

Otras fuentes en que se nutre la historia la constituyen las tradiciones de los pueblos, las que heredadas de generación en generación constituyen un gran aporte a la investigación histórica. Ejemplo de estas fuentes lo es el libro "Contribución al folklore" (1927), en dos tomos, de don Manuel Martínez-Moles. Por último, los monumentos, entendiéndose como tales los obeliscos, viviendas o cuevas habitadas por el hombre; puentes, altares, sepulcros o arcos, siempre de más valor para la historia los más antiguos y mejores conservados en su estado original. Una obra de este tipo es el libro "Cuevas y pictografías" ( $\sin$ fecha), del doctor Antonio Núñez Jiménez.

\section{FORMAS DE RESEÑAR LA HISTORIA}

Entre las formas más comunes de reseñar la historia se encuentran la crónica, en la cual se expone lo ocurrido en un gobierno o región limitada, por ejemplo "Crónicas 
de Santiago de Cuba", en diez tomos, de Emilio Bacardí Moreau; "Cuba: Crónicas de la Guerra"(1909), en tres tomos, del General de División del Ejército Libertador de Cuba José Miró Argenter y "En Cuba libre"(1938), crónicas del machadato, en dos tomos, por Gonzalo de Quesada Miranda.

Las efemérides en que se relata la historia por días, como la monumental obra "Anales y Efemérides de San Juan de los Remedios y su Jurisdicción", en 26 tomos del doctor José A. Martínez-Fortún Foyo y "Efemérides Médicas Cubanas" (1985), de la doctora Elena López Serrano.

Las décadas, en que se reseña lo ocurrido en un espacio de tiempo de diez años, como "Guerra de los Diez Años (1868-1878)" (1952), del maestro de historiadores cubanos doctor Ramiro Guerra Sánchez.

Las memorias, en que se narran los hechos históricos por alguien que actuó de algún modo en dichos sucesos, como "Memorias de la Guerra" (1989), por el General de Brigada del Ejército Libertador de Cuba Enrique Loynaz del Castillo, publicación póstuma realizada por su hija la poetisa Dulce María Loynaz Muñoz.

Pero la forma más usada por el historiador al escribir el informe final de su investigación es el ensayo, donde se exponen los hechos estudiados con el mayor rigor metodológico de búsqueda e interpretación, este es el caso de la reciente "Historia de Cuba", obra proyectada en cinco tomos, de las que han visto la luz cuatro hasta el año 2000, redactada por un colectivo de autores de la Escuela de Historia de la Universidad de La Habana, integrado, entre otros, por los doctores Eduardo Torres Cuevas, J orge Ibarra Cuesta, J osé A. Tabares del Real y José Cantón Navarro.

\section{VISIÓN DE LA HISTORIA}

Es aceptado por todos los autores que la historia se divide en: universal, general, nacional o particular, provincial, local, institucional, genealógica, biográfica y autobiográfica.

La historia universal, es la que comprende el estudio de todos los pueblos del planeta, como ejemplo de ella se citan dos obras verdaderamente monumentales, la "Historia Universal" (1875), del historiador italiano del siglo XIX, César Cantú, en diez gruesos tomos y la "Historia Universal" (I917-1922), dirigida por el historiador alemán Guillermo Oncken, en 46 tomos.

La general, en la que se estudian determinados pueblos unidos por un origen histórico, cultural o religioso, no se puede dejar de citar "Historia general de los pueblos de habla inglesa", del famoso político inglés, Premio Nóbel de Literatura y erudito historiador sir Winston Churchill.

La nacional, alcanza el estudio de un país o nación. "La Historia de la Nación Cubana" (1952), en diez tomos, dirigida por los doctores Emeterio S. Santovenia Echaide, Ramiro Guerra Sánchez, José M. Pérez Cabrera y Juan J. Remos Rubio, es un logro notable alcanzado por la historiografía cubana del siglo XX.

La provincial, se reduce a la de una provincia o estado. La obra "Pinar del Río"(1946), del doctor Emeterio S. Santovenia, que comprende la historia de la más 
occidental de las antiguas provincias, sirvió de modelo para que, por los años de la década de 1950 y a convocatoria de la antigua Academia de Historia de Cuba, se escribieran y publicaran las del resto de la provincias de entonces: "La Habana", por el doctor Julio Le Riverend Brussone; "Matanzas", por el doctor Francisco J. Ponte Domínguez; "Las Villas", por el doctor Rafael Rodríguez Altunaga; "Camagüey", por Mary Cruz de Augier y "Oriente", por J uan J eréz Villareal.

La local, comprende la historia de un municipio o de una de sus localidades. Cuba tiene una rica tradición de historias locales en las que sobresalen "Historia de La Habana. Desde sus primeros días hasta 1565" (1938) y "La Habana. Apuntes históricos" (1939), del erudito maestro de historiadores doctor Emilio Roig de Leuchsenring y no se puede dejar de citar al más prolífico de los historiadores locales de Cuba, al historiador médico doctor José A. Martínez-Fortún Foyo que publicó las de Remedios, Caibarién, Camajuaní, Yaguajay, San Antonio de las Vueltas, Zulueta y Placetas.

La de instituciones, en que se estudia un establecimiento de importancia histórica, ejemplos de esta división es "Historia de los Archivos de Cuba" (1949), en dos tomos, del capitán del Ejército Libertador y académico Joaquín Llavería Martínez; "La Universidad de la Habana. Bosquejo Histórico" (1919), del doctor Juan M. Dihigo Mestre e "Historia Documentada de la Universidad de la Habana. Síntesis histórica" (1965-1967), del doctor Luis F. Le Roy y Gálvez.

La genealógica, estudia una familia o grupo de ellas, como "El árbol genealógico de los Zambrana en Cuba" (1958), del profesor Gregorio Delgado Fernández o "Dignidades Nobiliarias en Cuba", del diplomático Rafael Nieto Cortadellas.

La biográfica, en que se estudia la vida de un personaje histórico como la antológica biografía "Martí, el Apóstol", del doctor Jorge Mañach Robato; la no menos antológica "Finlay"(1951), del historiador médico César Rodríguez Expósito y las muy numerosas del erudito historiador don Gerardo Castellanos García que comprende, entre otras, sobre I gnacio Agramonte Loynaz, Juan Bruno Zayas Alfonso, Calixto García Iñiguez, Gerardo Castellanos Lleonard, Néstor Aranguren Martínez, Francisco Gómez Toro, Adolfo del Castillo Sánchez y Serafín Sánchez Valdivia. Se destacan las muy documentadas "Vida y obra del sabio médico habanero Tomás Romay Chacón" (1950), del doctor José López Sánchez, maestro de historiadores médicos cubanos y "Don José de la Luz y Caballero" (1947), del profesor Manuel I. Mesa Rodríguez, último presidente de la antigua Academia de la Historia de Cuba.

Y la autobiográfica, en la que el propio personaje relata su vida, como "Recuerdos de mi vida" (1918), del Padre de la Oftalmología Cubana doctor Juan Santos Fernández Hernández; "Autobiografía" (1910), del general de división del Ejército Libertador de Cuba J osé Rogelio del Castillo Zúñiga, de gran valor histórico o el célebre "Diario Intimo", del filósofo de Ginebra Enrique Federico Amiel, de extraordinario valor psicológico.

\section{PERI ODICI DAD DE LA HISTORIA}

Es común entre los historiadores llamar edades a los períodos en que se separa la historia y ellas abarcan acontecimientos determinados por especial influencia en la marcha de la humanidad, la más aceptada clasificación en edades y sus límites es la siguiente: 
- Prehistórica o geológica, comprende desde las primeras noticias sobre el hombre que da la arqueología, hasta la aparición de la escritura y se ha dividido en los períodos Primario, Secundario, Terciario, y principios del Cuaternario. Otros autores la dividen en Edad de Piedra, subdividida en período Paleolítico o de la piedra toscamente tallada y Período Neolítico o de instrumentos de piedra pulimentada y Edad de los Metales, subdividida en Etapa de Bronce y Etapa de Hierro. El gran historiador inglés Robert Morgan la divide a su vez en: Época del Salvajismo, subdividida en Inferior, Media y Superior y Época de la Barbarie, igualmente subdividida en Inferior, Media y Superior.

- Edad Antigua, desde la aparición de la escritura o también desde las grandes migraciones y notables movimientos del hombre hasta la destrucción del Imperio Romano de Occidente en el año 476 de NE.

- Edad Media, desde la última fecha citada hasta la toma de Constantinopla por los turcos en 1453.

- Edad Moderna, desde ese hecho histórico de capital importancia para Europa, principalmente, hasta la Revolución Francesa de 1789.

- Edad Contemporánea, hasta la actualidad.

- Los historiadores marxistas la periodizan tomando en cuenta las formas de producción económica imperantes y así las nombran:

- Régimen de la Comunidad Primitiva, que abarca el mismo espacio de tiempo de la Edad Prehistórica de la anterior clasificación.

- Régimen Esclavista, comprende la anterior Edad Antigua. En el se estudia principalmente la historia de Egipto, Mesopotamia, Babilonia, Fenicia, Judea, Persia, India, China, Grecia y Roma.

- Régimen Feudal, desde la destrucción del Imperio Romano de Occidente hasta la Revolución Capitalista Inglesa de 1640 a 1660. Este período se ha subdividido a su vez en dos Edades: Media Temprana, del año 476 de NE hasta el inicio de los grandes descubrimientos geográficos(1492) y Media Tardía, hasta la Revolución Capitalista Inglesa.

- Tiempos Modernos, que abarca desde el final del período anterior hasta la Comuna de París en 1871.

- Tiempos Contemporáneos, hasta la Revolución Rusa de 1917.

- Historia de los Tiempos Actuales, hasta el presente.

Con la caída del régimen socialista en los países de Europa del Este esta periodicidad seguramente será modificada sobre todo con respecto a los dos últimos períodos.

\section{BI BLI OGRAFÍ A RECOMENDADA}

1. Carlyle T. El culto de los héroes. Buenos Aires: Ed. Tor. (Sin fecha).

2. Dahm I, Geissler A. Sociología para médicos. La Habana: Editorial Ciencias Sociales; 1985.

3. Hosak L, Krandzalov D. Fundamentos de la Historia. La Habana: Editorial Universitaria; 1965.

4. Langlois CV, Seignobos G. Introducción a los estudios históricos. La Habana: Editorial Universitaria; 1965.

5. Leiseca JM. Historia de Cuba. La Habana: Libr. Cervantes; 1925. 
6. Machado RJ. Como se forma un investigador. La Habana: Editorial Ciencias Sociales; 1988.

7. Pérez Cabrera J M. Fundamentos de una Historia de la Historiografía Cubana. La Habana. Imp. "El siglo xx". 1959.

8. Plasencia A. Lecturas escogidas de metodología. La Habana: Editorial Ciencias Sociales; 1975.

9. Plasencia A. Metodología de la investigación histórica. Sus fuentes y las ciencias auxiliares de la historia. La Habana: Editorial Estarcida; 1980.

10. Plejanov JV. El papel del individuo en la Historia. La Habana: Editora Política; 1963.

11. Reyes A. Mi idea de la Historia. Monterrey: Colec. Camelina; 1949.

12. Zanetti O, García A. Metodología de la investigación histórica. Los métodos cuantitativos. La Habana: Editorial Estarcida; 1980.

Recibido: 17 de enero de 2008.

Aprobado: 23 de junio de 2009.

Gregorio Delgado García. Escuela Nacional de Salud Pública. Calle Línea esq a I. El Vedado 10 400. La Habana, Cuba.

* Presentado en el Simposio "Arnaldo Tejeiro Fernández", Investigación Cualitativa en Salud Pública, 23 de junio de 2009. 